Discussion Paper No. 16-023

\title{
Ecological Sufficiency, Individual Liberties, and Distributive Justice: Implications for Policy Making
}

Peter Heindl and Philipp Kanschik

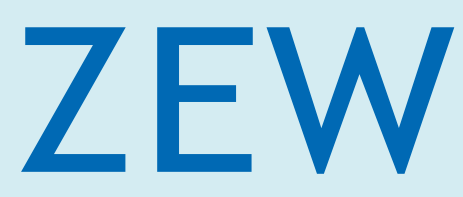

Zentrum für Europäische Wirtschaftsforschung $\mathrm{GmbH}$ Centre for European Economic Research 
Discussion Paper No. 16-023

\title{
Ecological Sufficiency, Individual Liberties, and Distributive Justice: Implications for Policy Making
}

\author{
Peter Heindl and Philipp Kanschik
}

Download this ZEW Discussion Paper from our ftp server:

http://ftp.zew.de/pub/zew-docs/dp/dp16023.pdf

Die Discussion Papers dienen einer möglichst schnellen Verbreitung von neueren Forschungsarbeiten des ZEW. Die Beiträge liegen in alleiniger Verantwortung der Autoren und stellen nicht notwendigerweise die Meinung des ZEW dar.

Discussion Papers are intended to make results of ZEW research promptly available to other economists in order to encourage discussion and suggestions for revisions. The authors are solely responsible for the contents which do not necessarily represent the opinion of the ZEW. 


\title{
Ecological Sufficiency, Individual Liberties, and Distributive Justice: Implications for Policy Making
}

\author{
Peter Heindl and Philipp Kanschik
}

March 2016

\begin{abstract}
- Abstract -
We investigate the prospects of voluntary ecological sufficiency for environmental and climate policy under the constraints implied by political liberalism. We find that freedom of choice restricts sufficiency to rather wealthy societies and that a sufficiency threshold cannot be derived by referring to the poor. Sufficiency can be in conflict with the demands of social justice, i.e. if the sufficiency threshold is below the social minimum implied by social justice. Benefits from sufficiency are highly related to individual perceptions. Such benefits cannot be expressed in a standard preference framework. Consequently, alternative measures of welfare and inequality are required if sufficiency is a significant phenomenon in society. 'Standard' environmental policies can have a pronounced interaction with voluntary sufficiency, i.e. if 'quantity regulation' is present. Overall, the voluntary notion of sufficiency causes a dilemma as sufficiency is largely a matter of civil society. However, voluntary sufficiency is expected to make important contributions to the preservation of ecological resources if properly balanced with social and environmental policies and framed by public discursive control.
\end{abstract}

Keywords: Ecological sufficiency; freedom; distributive justice; environmental policy; climate policy

Heindl: Centre for European Economic Research (ZEW), Department of Environmental and Resource Economics, L7 1, 68161 Mannheim, Germany, E-Mail: heindl@zew.de.

Kanschik: University of Bayreuth, Department of Philosophy, Universitätsstraße 30, 95447 Bayreuth, Germany, E-Mail: p_kanschik@hotmail.com.

Acknowledgements: We thank Wolfgang Buchholz, Goytom Abraha Kahsay, Klaus Rennings, and Rudolf Schüssler for their helpful comments. The financial support of the German Ministry of Education and Research (BMBF) in the project "Sozialpolitische Konsequenzen der Energiewende in Deutschland (SOKO Energiewende)," grant 01UN1204A and 01UN1204E, is gratefully acknowledged. 


\section{Introduction}

Ecological sufficiency (also abbreviated as 'sufficiency' in what follows) refers to a voluntary restriction of individual consumption motivated by ecological concerns. Behind the idea of sufficiency stands the compelling argument that the world's ecological resources are limited and that the current generation needs to assume responsibility for future generations and nonhuman species by preserving those resources. An eco-sufficient lifestyle implies assuming ecological responsibility on a personal basis and in everyday life.

Sufficiency explicitly considers an absolute decrease of consumption as part of an ecologically responsible way of living. The concept strongly contrasts with other approaches of environmental protection. These approaches usually focus on the preservation of ecological resources by means of technological progress and exogenous changes in incentives, such as carbon taxes, in order to cause changes in consumption behaviour. Technological aspects include increases in energy efficiency as well as the deployment of less resource-consuming technologies. However, a reduction of overall consumption is usually not the aim of 'standard' environmental and climate policies.

The focus of this paper is not to examine whether technology- and incentive-based environmental policies are sufficiently effective from an environmental perspective or whether a decrease in consumption or 'degrowth' is actually necessary. Given persisting global environmental problems, large uncertainty concerning the impact of environmental policies and increasing discussion on non-orthodox solutions (e.g. degrowth), we believe that eco-sufficiency could at least play some role for the protection of the environment and in combination with other measures and policies.

Assuming that eco-sufficiency is indeed considered a strategy to mitigate climate change, a number of theoretically and practically relevant issues emerge which we discuss in this article. In particular, these relate to the interaction of eco-sufficiency with other environmental policies, the measurement of welfare and inequality, standard economic preference-based frameworks, and widely accepted normative views on distributive justice and individual liberties. These aspects have received little attention so far in the academic literature. Consequently, our article aims at clarifying the relevant issues and points to potential tensions and challenges.

Given the wide range of topics, it is impossible to address all related aspects here. We rather aim at relating the discussion on eco-sufficiency to important topics in the existing literature in philosophy and economics and at identifying some problems of the concept. Moreover, our objective is to provide a starting point for further research and possible applications of ecosufficiency in practice as part of a 'climate policy mix'. The remainder of this article is organised as follows: Section 2 briefly discusses what eco-efficiency is. In Section 3, we discuss sufficiency in the light of the existing literature related to individual liberties and distributive justice, behavioural economics, social welfare and welfare measurement, and 'standard' environmental policies. We review and collect the most important arguments in Section 4. Section 5 concludes. 


\section{What is Ecological Sufficiency?}

Sufficiency can be described as the reduction of consumption on an individual level in order to contribute to ecological sustainability (Alcott, 2008; Fischer and Grießhammer, 2013). ${ }^{1}$ Sufficiency is understood as a change in consumption behaviour that augments other approaches of environmental and climate policy, for instance carbon taxation.

The prevailing view in economics is that a 'single price' on an environmental externality, such as greenhouse gas emissions, which is implemented by a central planning authority, is sufficient to fully internalise the externality (Baumol and Oates, 1971; Pigou, 1912). In a deterministic setup, regulation by prices (e.g. a carbon tax) and quantities (e.g. cap-and-trade) are equivalent (Montgomery, 1972), while the slope of marginal costs and benefits causes a comparative advantage of one instrument over the other in the presence of uncertainty (Weitzman, 1974). With respect to climate change, there is evidence that a (global) carbon price is preferable over cap-and-trade from the perspective of aggregated welfare (Hepburn, 2006; Hoel and Karp, 2002; Newell et al., 2003; Pizer, 2002). Targeted research and development (R\&D) subsidies for the promotion of low-carbon technologies are discussed as an important additional element of carbon prices (Acemoglu et al., 2012; Fischer and Heutel, 2013; Fischer and Newell, 2008; Fischer and Preonas, 2010). Environmental regulation, possibly augmented by R\&D subsidies, is expected to cause technological progress which will make goods and services less resource-intensive. From the perspective of neoclassical economic theory, there is no need for additional efforts by individuals for environmental protection, such as the reduction of consumption.

In contrast, advocates of sufficiency argue that rebound effects will (at least partly) offset ecological benefits from standard environmental policies, meaning that sufficiency is a necessary (but not sufficient) condition for achieving long-term environmental objectives. Sufficiency, as an additional measure augmenting other environmental policies, demands a change in lifestyle and usually implies a reduction of consumption and a shift of resources towards non-market and non-polluting goods. ${ }^{2}$ Overall, sufficiency is a behavioural change that goes beyond the change in economic activities which originates from environmental policies such as carbon taxes. The idea of sufficiency is consistent with the view that the transformation of a society towards ecological sustainability will require fundamental changes in the economy. Economic activities would have to take place under strict ecological constraints. This may include a shift in consumption towards non-market goods. However, the notion of an overall reduction in consumption is typically emphasised. Advocates of sufficiency further highlight that a less resource-intense lifestyle provides non-pecuniary benefits for individuals, which is an important argument in favour of sufficiency (Princen, 2005).

\footnotetext{
${ }^{1}$ Alternative definitions of sufficiency go even further and advocate a change in the overall style of living and the economic system, including a change in the perception of oneself, the social environment, and ecological resources (Princen, 2005; Sachs, 1993).

${ }^{2}$ This can be demonstrated on the basis of Kaya's Identity (Kaya and Yokobori, 1997). Alcott (2012) provides an interesting discussion on 'environmental structural change' with arguments in favour of a sufficiency strategy.
} 
Eco-sufficiency (as discussed in this paper) is characterised by four aspects: It is motivated by an ecological objective; it is an individual approach; it is consumption-based; and it is voluntary. The voluntary nature of sufficiency is disputed. For instance, Sachs (2009) or Princen (2005) do not pay particular attention to voluntariness. However, we will discuss sufficiency as a voluntary concept in the following as it has two advantages. First, voluntary sufficiency allows for a "bottom-up" approach regarding environmental protection without the need for centrally planned action. Second, voluntary sufficiency is compatible with political liberalism, if understood, in very broad terms, as a guiding principle of modern democratic societies. This perspective on sufficiency is the starting point of our discussion in Section 3 below. Nevertheless, we also examine the consequences of relaxing the assumption of voluntariness towards the end of the paper.

Please note that we need to distinguish between the individual choice to subscribe to ecosufficiency and the individual choice to define the concept (and demands) of eco-sufficiency. Voluntariness implies the former but not the latter. Thus, while voluntary sufficiency does not allow imposing a particular consumption level on individuals, it nevertheless implies a nonarbitrary specification of the 'sufficiency-threshold' (i.e. a consumption level which is adequate to meet some exogenously defined ecological objective) in order to provide guidance to individuals. People may still voluntarily commit to the sufficiency threshold, but sufficiency cannot be voluntary in the sense that people can define the concept in whatever way they want.

Based on this understanding of eco-sufficiency, we do not address the questions of how large a reduction in consumption needs to be to protect the planet's ecology, and how ecosufficiency is related to individual well-being. These issues tend to be the focus of existing literature on eco-sufficiency (especially the rebound effect). Without taking a stance on the necessity of eco-sufficiency, we simply note that there are increasing doubts about the effectiveness of 'standard' policy measures as global carbon emissions continue to rise despite all efforts. Under such circumstances, it seems worthwhile to examine the feasibility and implications of seemingly 'unorthodox' approaches like eco-sufficiency as part of a policy mix which is embedded in a broader political and economic framework.

Such approaches have received increased attention, especially the so-called 'degrowth' movement. Eco-sufficiency is akin to degrowth in calling for abandoning economic growth as a means to foster environmental sustainability, justice, and well-being (Demaria et al., 2013). On environmental matters, advocates of eco-sufficiency and degrowth agree that technological advancements cannot decouple current production and consumption patterns from ecological damage. Degrowth and eco-sufficiency also converge on the idea that consuming less can yield additional private benefits, in addition to ecological benefits.

However, degrowth activism has a broader scope and a more radical outlook than ecosufficiency, as it relates to democratic theory, the concept of development, global justice, and the meaning of life (Demaria et al., 2013; Kallis, 2011). The scope of eco-sufficiency is narrower, focusing on ecology- and consumption-related issues. Thus, it seems prima facie possible to fit eco-sufficiency into existing liberal economic and policy frameworks rather 
than integrating it into a more radical degrowth approach, which is unlikely to leave the foundations of current frameworks intact (see e.g. Salleh, 2011).

Hence, we focus on voluntary sufficiency in relation to individual liberties, social justice, welfare, and 'standard' environmental policies. In particular, we examine possible tensions between sufficiency (understood as a guiding principle with direct implications for policy making) and political liberalism (understood in very broad terms as a guiding principle of modern democratic societies).

\section{Problems Related to Ecological Sufficiency}

\subsection{Freedom, Poverty and Justice}

Sufficiency, as understood here, is not defined by mandatory restrictions of consumption but rather by free choice, thought as a voluntary individual decision. Freedom of choice - to be a meaningful concept - requires the absence of hindrances or physical obstacles. In other words, a set of alternative choices must be actually available to a person (Berlin, 1969; Pettit, 2012). Otherwise, freedom of choice would be merely a formal ideal without implications for reality.

This has direct implications for the concept of voluntary sufficiency. To make a voluntary decision about whether to live sufficiently or not requires that both options are available. If a person lacks the ability to live above the consumption level implied by sufficiency, the person will be unable to choose not to live sufficiently. For instance, we could think about a person who involuntary lives in absolute poverty. Although his or her consumption is far below the global average, we cannot say that the person lives in accordance with sufficiency due to a lack of freedom of choice. Living according to sufficiency, therefore, can only refer to people who initially live in affluence.

This has another important implication. A person who lives in poverty cannot serve as a reference or benchmark for any definition of a sufficient life. This is essential because sufficiency is sometimes motivated exactly by such a comparison, e.g. with reference to the carbon footprint of people living in least developed countries. Such a comparison is invalid in so far as it focusses predominantly on the ecological impact of the life of the poor. Yet, this partly omits other important aspects of well-being, and fully omits the economic, social, and psychological consequences of poverty. Stern (2015) considers poverty alleviation the key for a successful global climate policy: "If we fail on one, we will fail on the other" (p. 1).

Eco-sufficiency requires a meaningful specification of the 'sufficiency threshold' in order to explain how much consumption is conceived as 'enough' to avoid deprivation and, at the same time, is compatible with the ecological boundaries of the planet. Eco-sufficiency itself imposes restrictions on individual consumption that 'help to respect the earth's ecological boundaries', as phrased by Fischer and Grießhammer (2013, p. 10). This effectively translates into an upper bound of consumption, namely an ecologically sufficient consumption threshold which should not be exceeded. 
Thresholds also happen to play a significant role in philosophical theories of justice and the ethics of distribution. However, social justice is often discussed in a way that implies a lower bound of consumption which is often conceptualised as a social minimum. The importance of a social minimum is recognised by many different scholars of social justice (Anderson, 1999; Dworkin, 2000; Nussbaum, 1999; Rawls, 1993), and it is an instrument of social politics in the modern welfare state. ${ }^{3}$ Furthermore, a lower-bound threshold is an explicit part of the philosophic concept of sufficientarianism (Frankfurt, 1987; Huseby, 2010; Shields, 2012), which is not to be confused with eco-sufficiency. ${ }^{4}$

Any conception of a social minimum will imply a minimum level of consumption that corresponds to a life free of material deprivation. If we accept this idea and, at the same time, subscribe to the ideals of eco-sufficiency, we have two possible outcomes. The first is a situation in which the ecological sufficiency threshold is above the consumption threshold implied by a social minimum. In this case, the concept of eco-sufficiency does not interfere with the idea of a social minimum.

The second situation is one in which the (minimum) consumption threshold is above the ecosufficiency threshold. In this case, eco-sufficiency would necessarily imply some sort of deprivation which is obviously in conflict with the idea that people should live free from deprivation, and thereby is in conflict with social justice. In this situation we face an ethical dilemma. Members of society will likely ascribe a different moral weight to the consumption thresholds implied by social justice and eco-sufficiency which can cause conflict and requires discourse.

Furthermore, it is likely that the thresholds will be dependent on each other in the sense that social justice serves as a higher-order condition for the definition of an eco-sufficiency consumption threshold and vice versa. In other words, when defining the eco-sufficiency threshold, we need to make sure that it is above the social minimum (Stern, 2015). Voluntary eco-sufficiency is unlikely to be accepted, if it violates public common sense judgment on justice and poverty. It is impossible to pin these notions down in an objective way, but taking them into account is instrumental in establishing voluntary sufficiency. This aspect is largely underexposed in the public and academic debate so far and moreover, it has implications for the measurement of welfare and inequality, an issue to which we return below.

\subsection{Individual Preferences and Volitions}

Eco-sufficiency is highly related to the individual perception of benefits from living sufficiently. Thus, it is essential to ask from where these benefits originate. Usually two types of benefits are discussed in relation to sufficiency: First, ecological benefits which have the notion of a public good, i.e. the protection of ecological resources; and second, private non-

\footnotetext{
${ }^{3}$ For instance, German minimum social security allowances are defined as the absolute minimum threshold, based on the average consumption of households in the lower two deciles of the income distribution.

${ }^{4}$ Sufficientarianism in philosophy can be summarised by the claims that i) it is important that people live free from deprivation, ii) that we have weighty reasons to secure at least enough of some goods, and iii) that once people have secured enough, our reasons to provide them with further benefits are weaker than before (see Shields, 2012, pp. 105-111). Kanschik (2016) argues that sufficientarianism and eco-sufficiency should be strictly distinguished because they are incompatible (Kanschik, 2016).
} 
pecuniary benefits which are related to the intrinsic value of 'good' behaviour in relation to ecological objectives.

There are some important methodological issues in relation to these benefits: Uncoordinated public good provision by individuals usually leads to underprovision of public goods because of free-riding incentives (Cornes and Sandler, 1996, p. 157). On the one hand, this implies that sufficiency alone will likely not yield adequate levels of environmental protection because of the underprovision problem. On the other hand, the problem could also corrupt the willingness of people to live sufficiently because of the expectation of underprovision. Thus, under standard preferences - assuming purely rational and self-interested agents - ecosufficiency could be deemed irrational or ineffective.

Although the 'homo economicus' is the backbone of economic theory, economic activities motivated by other-regarding preferences, social norms, or personal identity have received attention under the label of 'behavioural economics' for decades. They can help to explain behaviour as implied by eco-sufficiency. Behaviour which is 'good', charitable or pro-social is not only motivated by pure altruism. It also serves an economic purpose through impure altruism which implies that private and public benefits occur from 'doing good' (Andreoni, 1990). Individuals also may behave pro-socially because they want to 'feel good' and reassure themselves of being a 'good person' (Bénabou and Tirole, 2011, 2006; Kahsay and Samahita, 2015).

In other words, doing 'good things' serves an economic purpose, for example through the channel of esteem which can be interpreted as a scarce resource (Brennan and Pettit, 2004). Other-regarding preferences are influenced by cultural identity and social distance (Buchan et al., 2006). Trust and fairness are important in the presence of weak economic governance (Dixit, 2004). This is of great importance with respect to climate change where fair mutual treatment is crucial for international negotiations (Lange and Vogt, 2003; Lange et al., 2010). These findings suggest that private benefits from sufficiency might be contingent on the personal perception of a good life but also on the social and cultural environment. Individual incentives to live sufficiently, thus, depend on the perception of pro-environmental behaviour in society.

Building 'green clubs', bundling of public and private goods, or matching of contributions to a public good can significantly improve aggregated public good provision and reduce problems of free riding (Buchholz et al., 2012; Dixit and Olson, 2000; Guttman, 1978; Nordhaus, 2015; van't Veld and Kotchen, 2011). For instance, bundling of private and public goods (which yields an impure public good in aggregate) can be observed in relation to organic products or products which are produced under fair social conditions and/or which are particularly environmentally friendly. To the best of our knowledge, there is no direct application to the case of ecological sufficiency, but the literature in the field of behavioural economics suggests that voluntary and individual pro-environmental behaviour can generate 
significant private benefits, e.g. by 'signalling' of pro-environmental behaviour and a positive perception by others. ${ }^{5}$

A prerequisite for such behaviour is the existence of pro-environmental attitudes and values which motivate 'green' behaviour. Philosophy is explicitly concerned with the question of what motivates individual behaviour. According to Frankfurt (1971), the difference between persons and other beings lies in the structure of the will. The capacity of a person to reflect about his or her own identity - to form a will about a will - is central in this respect. Such 'higher-order volitions' are volitions about (lower level) volitions, typically guided by longterm convictions and reflective reasoning. Eco-sufficiency will typically (but not necessarily) include volitions of higher order, for instance the volition to act in a way that is compatible with the ecologic capacity of the planet.

Various philosophers regard higher-order volitions as central to freedom of self (Frankfurt, 1971; Pauen, 2007; Pettit, 2001a). Acting in a way others approve of may bring about a positive reputation or cause a 'good feeling' but it does not necessarily comply with freedom. Freedom of self requires volitional control. This implies that an agent is not merely a bystander or onlooker, but can fully identify with a choice in the sense of being the author of a choice or action (Pettit, 2001b, p. 64). The congruence of one's actions and one's convictions, hence, marks a condition for freedom. The Freedom of self also requires rational control, i.e. the absence of pathologies as described by Pettit (2001b, p. 43) or 'being fit to be held responsible for one's actions' in the sense of an intrapersonal capacity for free action. Rationality is not thought of here as 'perfect', but it requires that beliefs will be updated if there is new relevant information. If both rational and volitional control are present, one can argue that a) there is a fully voluntary choice (which is of importance in light of the discussion above), and b) that the desires and beliefs of a person - the idea of what 'good' behaviour is are what matters with respect to the perception of the benefits ascribed to eco-sufficiency. In particular, this last aspect can be understood as an important part of the identity of a person with great influence on truly voluntary decision making.

The importance of identity for decision-making is also acknowledged in economics. Akerlof and Kranton (2000) argue that identity invokes an externality with signals generated through identity in relation to others and that identity can change (or influence) preferences as used in economics. Akerlof and Kranton state that the choice of identity is one of the most important economic decisions people make (p. 717). In this context, the work of Frankfurt (op. cit.) examines how such choices are made. Akerlof and Kranton (op. cit.) show that identity can explain economic outcomes and individual decisions to a large extent. Examples include the choice of occupation in relation to gender identity (p. 732), the economics of the household (p. 745) or even the economic drivers of poverty and social exclusion (p. 737).

Several implications follow from the perspective that eco-sufficiency generates benefits which are highly related to individual values embedded in higher-order volitions. First, it is

\footnotetext{
${ }^{5}$ Pro-environmental behaviour may also include reduced consumption. Reduced consumption could be understood as a 'donation' (giving up private funds) to do 'good' (protecting the environment). An open empirical question is if individual pro-environmental behaviour (e.g. eco-sufficiency) might possibly 'crowd out' the pro-environmental behaviour of others.
} 
possible that a person acts against the higher-order volition in some situations. For instance, a person could occasionally buy convenience products which are not eco-friendly, even if he or she in principle objects such behaviour for ecological reasons. This is an important reason why revealed preferences may be unsuitable to identify eco-sufficient behaviour empirically. ${ }^{6}$ Second, higher-order volitions can originate from a 'perfectionist view' as they are related to individual moral ideals of a good life in accordance with the ecological capacity of the planet. This implies that the benefits that might occur from eco-sufficiency cannot be generalised to all members of society. Third, eco-sufficiency will not necessarily require benefits which are tangible in conventional economic terms and can include non-material benefits. In this light, benefits of an eco-sufficient lifestyle should be understood in a broader sense as benefits which are related to the individual perception of a good life. Finally, this implies that there are limits to the interpersonal comparison of benefits from eco-sufficiency. This also has important implications for possible empirical work, e.g. the valuation of non-pecuniary benefits and aggregated welfare which would require some type of interpersonal comparisons (see also Rawls, 1999, p. 13).

\subsection{Public Discourse and Social Outcomes}

Conceptualising eco-sufficiency as volition of higher order imposes strong limitations on interpersonal comparison, but it opens the floor for public discourse. Discourse seems necessary, since there is the need to agree upon a 'sufficiency threshold' which also is in accord with considerations of social justice as discussed above. Discourse can be limited to the question of what choices should be made, but it can also include a discussion on why these choices are made (List, 2006). Discourse about eco-sufficiency and its benefits, when described as a largely individual concept, would explicitly require including the 'why' into the discourse to account for social norms which might motivate eco-sufficiency as discussed above. Discourse between proponents of eco-sufficiency and others could raise awareness for the ecological and social benefits of a sufficient life and promote understanding of the individual motives of proponents of eco-sufficiency.

An important aspect of the discourse is that it needs to be 'informed'. In many cases, positive attitudes towards eco-sufficiency are based on beliefs about climate change. Citizens (and experts) need information regarding the actual relevance and severity of the problem as a basis for coordinated public action. This, in particular, is a problem in relation to the design of climate change policies and the definition of a possible sufficiency threshold. The position of people in the far future needs to enter any assessment of the impacts of climate change and the required action today (Posner and Weisbach, 2010). The standard economic tools for such assessments are 'Integrated Assessment Models'. However, these models deliver different results regarding the optimal response to climate change and the social cost of carbon (Nordhaus, 2008; Stern, 2008; Tol, 2011). There is no consensus in the literature about the actual impact of climate change and the required action (Tol, 2012). But there is consensus that strong losses are to be expected if temperatures increase significantly, that there will be a

\footnotetext{
${ }^{6}$ Any empirical assessment of revealed preferences requires a law of large numbers in order to derive 'average' preferences or volitions. Since we have argued that aspects of identity and higher-order volitions are relevant for the benefits that a person ascribes to eco-sufficiency, revealed 'average' preferences are of little use.
} 
strong negative impact of climate change on low-income countries, and that there is vast right-skewed uncertainty in the assessment of climate change damages (Tol, 2009). There even is a discussion about possible 'catastrophic risks' of climate change (Weitzman, 2014). Thus, uncertainty about the impact of climate change causes severe limitations for an informed discourse in the sense of a rational collective decision process as it increases the likelihood of rational disagreement.

Moreover, there are some important moral aspects that need to be addressed, i.e. the 'discount rate' which weighs costs and benefits in the future. Sen's (1967) 'assurance problem' implies that optimal social discount rates are not necessarily equal to market interest rates (see Posner and Weisbach, 2010, Ch. 7). ${ }^{7}$ Also questions regarding the historical responsibility of different countries or groups of countries for climate change are relevant (Schüssler, 2011). Another important aspect is related to poverty and deprivation in relation to climate change policies. Either with regard to the assessment of social welfare in aggregate (Adler and Treich, 2015) or in order to avoid individual deprivation in relation to energy services. Adequate indicators of deprivation would be required to tackle deprivation. However, the literature on this issue appears to be underdeveloped (Heindl and Schuessler, 2015).

Given large uncertainty and the moral import of the above-mentioned aspects, the individual perceptions of the problem of climate change and the adequate response diverge and public discourse is needed (Stern, 2015). Within a society, consensus may be reached regarding 'standard' policies to address the problem of climate change, such as the introduction of a carbon price, on the basis of economic arguments. ${ }^{8}$ However, some members of society may wish to contribute beyond the standard policy based on individual ancillary action in the form of eco-sufficiency.

There are two further, more general aspects which are of particular importance in relation to public discourse on eco-sufficiency. Pettit (2001b) describes 'discursive control' as a necessary condition for freedom of action, self, and the person. He remarks (2001b, p. 101): "Did we praise or blame an agent only because of hoping to reinforce or alter their behaviour [...] then praising or blaming someone would be a highly disrespectful act and would be a reasonable ground for resentment." This refers to the possibility of strategic manipulation in the discourse which is to be avoided. This does not imply that humoristic, satiric or provocative remarks are generally inadmissible in a (public) discourse. Yet, ultimately, any such remarks should relate to reasonable arguments, as opposed to defamation and manipulation.

\footnotetext{
${ }^{7}$ Sen discusses the 'isolation problem,' a simple prisoners dilemma type of game in which a Pareto-inferior outcome is the result of the strict dominance of an individual strategy (Sen, 1967, p. 113). Sen further demonstrates that it would be possible to increase welfare without the need for compulsory enforcement, meaning to overcome the 'isolation problem,' if everyone would be assured that the other agents make decisions which maximise joint welfare (see also Bowles, 2004, p. 24). In the presence of an externality, the market outcome will be different, depending on if the externality is internalised or not. Under the 'assurance problem' and in the absence of enforcement, the externality will not be internalised because of the dominance of an individual strategy. Therefore market interest rates - as a result of 'isolated' Pareto-inferior decisions - omit the external effect.

${ }^{8}$ This includes optimal abatement volumes as well as the design of economic instruments to achieve emission reductions.
} 
A second aspect is that the discourse needs to be open, in so far that all possible options as outcome of the discourse need to be available (Schüssler, 1996). It is important to avoid situations in which choices are limited in the sense that they are restricted to different versions of (or policies related to) sufficiency but do not consider non-sufficiency. It is inevitable for a respectful discourse to openly discuss advantages and disadvantages of a sufficient versus a non-sufficient lifestyle in order to preserve individual freedom in all relevant domains. A comprehensive deliberative discourse provides the basis for proponents and critics of sufficiency alike to rationally defend their views.

\subsection{Welfare and Welfare Measurement}

Above, we have argued that eco-sufficiency cannot be represented in a standard first-order preference framework. In the discussion on eco-sufficiency, it is also emphasised that such frameworks tend to be biased towards 'priced market goods', i.e. if the choice set under consideration consists only of such goods. ${ }^{9}$ Many things which are important to us do not come with a price tag on (Sandel, 2012). Examples are deep friendship, the affection of a beloved person, or the love and attention a child receives from his or her parents. These things can be described - in broader economic terms - as externalities: non-traded goods without a market price. Neoclassic economic theory largely fails to account for these types of goods.

What does this imply for sufficiency? The fact that ecological goods are (often) non-priced goods is independent from the value (be it material or non-material) that a person ascribes to other non-priced goods. This makes it difficult to evaluate how weighty eco-sufficiency is in comparison to other goods, and how potential trade-offs should be assessed. To this end, it is not clear why ecological aspects should play a prominent role in the discussion on non-priced goods. Ecological aspects play a role among other things. Thus, we cannot derive absolute priority of ecological goods over other goods in a positive way. As argued above, the value and priority of ecological non-priced goods to a large extent originates from individual higher-order volitions and the perception of behaviour by peers.

Because of this, voluntary sufficiency leads to a problem related to traditional approaches of welfare and inequality measurement. The distributional outcome of eco-sufficiency within society as a whole hinges on the number of people who choose to live sufficiently and the number of people whose consumption remains unchanged. Under the assumption that ecosufficiency generally implies a decrease in individual consumption, we would observe increasing inequality in society as a whole if a significant number of people chose to live sufficiently, while other members of the same society maintained the initial consumption patterns. We can think about this in terms of inequality, as depicted by the Lorenz curve. If more people adopted an eco-sufficient lifestyle, we would observe a concentration in the lower left corner of the consumption-based Lorenz curve, indicating an increase in inequality which is usually interpreted as an undesirable social outcome. ${ }^{10}$

\footnotetext{
${ }^{9}$ A similar argument can be found in the discussion on economic inequality. See Frankfurt $(2015$, p. 11) for a recent account.

${ }^{10} \mathrm{An}$ interesting aspect is that we would likely observe a rather equal distribution of consumption within the group of eco-sufficientarians if the equivalised consumption threshold per capita was set in a similar way by ecosufficientarians by virtue of ecological objectives. If eco-sufficientarians tend to value equality as such, this can
} 
However, under the proviso that eco-sufficiency is a voluntary and non-deprived concept as developed above, people would still be content (or would become truly content just because they live sufficiently). Thus, in the case of sufficiency being a broader phenomenon in society, it would be necessary to reconsider the interpretation of overall inequality and relative poverty. The common interpretation that increasing inequality of income or consumption indicates a negative development would not hold any more in this case.

This observation provides evidence that there is a need for alternative approaches to measure welfare and inequality under two conditions. First, eco-sufficiency and related concepts must be a significant phenomenon in society in order to provide a justification for alternative approaches to welfare measurement. Second, sufficiency can only be understood within a normative framework that avoids the identification of lower income and consumption with welfare loss and which is further able to depict welfare gains achieved by a sufficiency lifestyle. A purely monetary approach to welfare measurement will likely underestimate the benefits perceived by proponents of sufficiency (Fleurbaey, 2009, p. 1035). ${ }^{11}$ Under such an approach, it is also inevitable to distinguish involuntary deprivation from voluntary sufficiency. This requires interpersonal comparison of individual volitions and intentions. The prevailing view in economics is that such empirical comparisons are very complicated, in particular when based on individual values (Arrow, 1963; Cooter and Rappoport, 1984). But interestingly, there is some overlap with Wicksell's (1958) theory of just taxation which also requires information on individual valuation of public goods in comparison to other goods.

Wicksell takes the view that the willingness to contribute to a public good (and hence the benefits from public good provision) differs between individuals. Consequently, and as an outcome of fair and free cooperation (Buchholz and Peters, 2007), optimal contributions to public good provision are 'individual' and contingent on personal preferences (Johansen, 1963; Lindahl, 1958). If eco-sufficiency is interpreted as an individual action in accordance with individual preferences, the connection to Wicksell's theory is obvious and there are a number of important implications. Differences in individual efforts are, for instance, optimal from an economic viewpoint. Welfare would be decreased if all people were forced to contribute to public good provision in the same way. Public good provision according to individual preferences further provides the basis for 'unanimous approval' of public good provision, which can be understood as a democratic legitimation and an outcome of public discourse. The willingness to contribute to a public good ('Lindahl price') could also serve as a yardstick for welfare measurement. Another important implication of Wicksell's theory has already been discussed in Section 3.1, namely that such an approach necessarily requires justice in the initial distribution of income and wealth. To put it in the words of John Rawls

\footnotetext{
be an additional benefit from eco-sufficiency, at least if a social comparison is made within the group of ecosufficientarians.

${ }^{11}$ Because eco-sufficiency may involve non-pecuniary benefits, any money-metric based approach to welfare measurement (Fleurbaey, 2009, pp. 1036-1055) appears problematic. This also includes approaches such as 'green accounting', in particular if two different populations (proponents and opponents of sufficiency) are compared (Fleurbaey, 2009, p. 1036). Alternative approaches, such as measures of subjective well-being or happiness may - at best - represent a rough proxy for welfare in this context and may possibly downplay the role of consumption (Fleurbaey, 2009, p. 1056). Sen's (1987) capability approach has the merit of being rather flexible (Fleurbaey, 2009, p. 1067). Bernheim and Rangel propose a model of behavioural welfare economics which could be of interest in the context of eco-sufficiency (Bernheim, 2009).
} 
(1971, p. 250): “Without this important proviso, [Wicksell's principle] would have all the faults of the efficiency principle [...].” The problem, however, is that the individual valuation and willingness to pay for a public good (such as climate protection) are hard to identify. Thus, further advancing concepts for alternative welfare measurement and ecological valuation under the conditions rehearsed above are important aspects for future research.

\subsection{Implications for Environmental Policy}

Policies for the protection of the environment often consist of standards for pollution control and/or technology deployment, but price- or quantity-based policies play an important role as well. These policies have in common that they aim at reducing polluting activities but do not necessarily imply a reduction in overall consumption. Price and quantity regulation further impose restrictions on pollution in aggregate, but they do not impose restrictions on a personal basis.

It is useful to examine under which circumstances ecological benefits from an eco-sufficient lifestyle are actually transferred into ecological benefits for society as a whole and if there are situations in which this can be circumvented by 'standard' environmental policies. ${ }^{12}$ Alcott (2008) states that sufficiency could cause adverse effects through what is known as 'general equilibrium effects' in economics. If many people consumed less motivated by sufficiency, prices of goods would decrease which would make goods more affordable for those who do not subscribe to a sufficient lifestyle. Thus, non-sufficientarians could consume more and the ecological benefits generated by sufficiency would be reduced or fully compensated because of a 'rebound effect' in consumption or carbon leakage. ${ }^{13}$ This argument follows a similar logic as the 'green paradox' does on a macroeconomic level (Ritter and Schopf, 2013).

Alcott's concerns are sound in terms of economic theory and could be described as a 'sufficiency paradox'. But there is another aspect which is relevant in practice. While the rebound effect described by Alcott hinges on the magnitude of changes in prices, substitution of goods, and saving rates, it is further possible that the mere existence of environmental policies could render sufficiency ineffective to some extent. In particular, this is the case under quantity regulation of pollutants under which an economy-wide 'cap' on pollution is imposed (see also Perino, 2015).

An example for quantity regulation is the European Emissions Trading Scheme (EU ETS). The amount of EU-wide annual greenhouse gas emissions of utilities and industrial installation is 'capped' under the EU ETS, and companies are allowed to trade emission permits. The scheme is fairly cost-efficient and effective in the sense that the amount of EUwide emissions per year will not exceed the cap. However, the cap on emissions is

\footnotetext{
${ }^{12}$ In such a situation, referring to the framework of standard preferences, choosing a sufficient lifestyle would be irrational because it does not cause any ecological benefit.

${ }^{13}$ The rebound effect occurs if resource saving technology or behaviour does not lead to a corresponding reduction in overall resource consumption because of changes in prices and income. The 'Green Paradox' is related to this perspective via Hotelling's rule of resource extraction (Hotelling, 1931). Carbon leakage occurs if greenhouse gas emissions are increased in countries without climate policy, because production is shifted from countries with emission control policies to countries without strict emission control.
} 
independent of individual consumption behaviour. ${ }^{14}$ If people chose to reduce the consumption of $\mathrm{CO}_{2}$-intensive goods, the price at which allowances are traded would decrease, but the amount of overall emissions would remain unchanged. This occurs because the quantity of annual emissions is exogenously given by the cap, while the price of emissions is endogenous. The effect was previously discussed in relation to differing ambitions in climate policy across EU-member states where similar problems arise (Heindl et al., 2015). Thus, eco-sufficiency is ineffective under quantity regulation if the 'cap' is exogenous.

However, sufficiency will be effective under price regulation. Price regulation refers to policies which directly impose a price on polluting activities such as carbon taxes. The tax makes polluting activities more expensive vis-à-vis other activities and by that shifts aggregated demand towards more environmentally friendly goods so that a reduction of pollution is achieved by virtue of the tax. Now, if a person lowers consumption motivated by eco-sufficiency, the tax rate will remain unaffected, while the quantity of emissions will be endogenous. In this case, the tax provides unchanged incentives to lower demand for those who do not subscribe to sufficiency, independent of ancillary emission reductions on a personal level. Sufficiency will be effective if it causes a more pronounced reduction in consumption, as would have been the case by virtue of the tax alone. ${ }^{15}$

The academic debate on 'prices versus quantities' was initially motivated by uncertainty of costs and benefits in environmental regulation (Weitzman, 1974) and was later expanded to policy interactions between jurisdictions (Heindl et al., 2015). Sufficiency adds another important facet to the discussion. From this point of view, quantity regulation with an exogenous 'cap' could cause problematic policy interactions if sufficiency was expected to make a significant contribution to achieve environmental objectives. In such a situation, 'standard' policies would need to take interactions with voluntary sufficiency into account in order to maximise the joint environmental benefit under both approaches.

\section{Synthesis: The Prospects of Voluntary Sufficiency}

If understood as purely voluntary, sufficiency of course has a proper place in a liberal society and can be a non-deprived concept. From this perspective, claims about the potential incompatibility of sufficiency with liberal values and a democratic society appear implausible. Nevertheless, we have identified a number of issues which are relevant in practice. Three aspects are of particular importance:

First, individual liberties and the demands of social justice limit the applicability of sufficiency to some extent. Freedom of choice, as described above, requires that all relevant options are physically available. This implies that a voluntary decision to live sufficiently also

\footnotetext{
${ }^{14}$ In a democratic society, the 'cap' is usually the outcome of a political decision process. It is of course possible that climate policy becomes more (or less) ambitious over time as an outcome of public discourse. However, the bargaining process is usually a collective process. Individuals have little influence on specific climate policy targets in a certain point of time. This is the reason why we consider the 'cap' as exogenous.

${ }^{15}$ We do not want to claim, in this context, that price regulation is generally more effective than quantity regulation, but only examine interactions with voluntary sufficiency. One problem of price regulation is that it leads to increased tax revenues. These may be spent in a way that creates additional emissions by the government or by citizens if the money has to be channelled towards them via tax reductions. Thereby, the positive environmental effect of a price scheme could be cannibalised (Wackernagel and Rees, 1997, p. 20).
} 
requires the option to live non-sufficiently. From this perspective, the carbon footprint of a person which involuntary lives in poverty is unsuitable as a reference for a sufficient life. Sufficiency in the sense of 'having just enough' implies an upper threshold of consumption in accordance with the ecological capacity of the planet. This can cause a conflict with the widely accepted demands of social justice, often described as a social minimum, which imply a lower threshold of consumption. If the sufficiency threshold is below the threshold implied by a social minimum we face a moral dilemma. The relation and interdependence of both concepts has received little attention so far. Since there is the possibility that both concepts are incompatible in practice, theoretical and empirical work related to sufficiency and social justice is required.

Second, sufficiency cannot be comprehensively expressed in a standard preference setup, and its implications need to be a subject of public discourse. Sufficiency as a non-deprived concept requires non-pecuniary benefits from living sufficiently to compensate for a reduction in consumption. It is unclear how such a concept is related to the standard preference framework as used in (neoclassical) economics. This also limits the options for empirical assessments of sufficiency, since the related benefits are not directly observable. Concepts as found in the field of behavioural economics could help to overcome this problem but, to the best of our knowledge, there are no direct applications to sufficiency so far in the literature. The perspective of sufficiency as a highly individual concept causes severe limitations for policy making, but interference in the private domain (i.e. taking the form of non-voluntary sufficiency in the sense of publicly uncontrolled obligations) is to be avoided in order to preserve individual liberties. We have proposed public discourse as a potential solution to this problem. The proposed comprehensive deliberative discourse is understood as an ongoing discourse about the value of non-priced goods, the demands of ecological sustainability, uncertainties of climate change, and other relevant economic, social, and normative aspects. The discourse is not only limited to the question of what should be done; it also explicitly includes the question of why members of a society take a specific view or assign a certain weight to ecological objectives. Such a discourse could augment the existing discourse on how to define 'standard' environmental policies which is a more minimal liberal type of discourse.

Third, sufficiency can have important implications for the measurement of welfare and inequality as well as for the design of 'standard' environmental policies. Sufficiency, if a broader phenomenon, will make the application of alternative measures of welfare necessary. This occurs because standard measures of equality would likely indicate increasing inequality in society as a consequence from sufficiency, and underestimate non-pecuniary benefits. However, the standard interpretation of increasing inequality as a negative social outcome could not be maintained under voluntary sufficiency. Alternative measures would require interpersonal comparisons to account for non-pecuniary benefits, which are hard to identify, particularly if interpreted as result of higher-order volitions. To some extent, similar difficulties as in Wicksell's theory of just taxation occur, e.g. how to identify the individual valuation of public goods (Hansjürgens, 2000). Furthermore, existing environmental policies, i.e. quantity regulation, can cause sufficiency to be ineffective or even unnecessary (Perino, 2015). There is strong interaction between 'standard' policies and voluntary sufficiency. In 
order to maximise the joint ecological benefits from standard policies and individual ancillary voluntary approaches, these interactions should receive increased attention by policy makers. In particular, negative effects of standard policies on voluntary sufficiency should be avoided.

Overall, the protection of the environment obviously requires some degree of domination under discursive public control. However, we have taken the perspective that uncontrolled domination in the private sphere must be avoided in order to preserve individual liberties and the voluntary notion of sufficiency (Pettit, 2012). This implies that an individual must be able to engage in favour or against specific actions in the discourse. Moreover, there has to be freedom of individual action under the constraints of the publicly controlled law. Therefore, the prospect of sufficiency hinges on the aspect of voluntariness to a large extent. Different definitions of sufficiency exist. While some stress the voluntary notion of sufficiency (Fischer and Grießhammer, 2013), others explicitly hold perfectionist views without emphasising aspects of voluntariness (Princen, 2005; Sachs, 2009; Salleh, 2011). ${ }^{16}$ In the light of the arguments mentioned above, it is essential to distinguish these different versions of sufficiency as they will have different implications in many aspects.

Specific policies motivated by sufficiency need to undergo examination to study if they will interfere with the voluntary notion of sufficiency as discussed above. This includes soft measures or nudging as well as more comprehensive policies. ${ }^{17}$ Voluntary sufficiency has the potential to deliver important environmental benefits while being compatible with 'standard' environmental policies, the demands of social justice, and individual freedom. Non-voluntary sufficiency would likely increase positive ecological effects to a strong extent. This, however, would cause severe restrictions in other parts of private and social life, which are incompatible with political liberalism (Rawls 1985). Thus, the concept of eco-sufficiency may face a dilemma, meaning that it either has limited relevance for policy making or it is incompatible with the values of a liberal and pluralist society.

\section{Conclusion}

This article investigates a number of so far underexposed problems related to eco-sufficiency and possible applications of eco-sufficiency in practice. In particular, we focus on the implications for the design of standard environmental policies, wealth and inequality measurement, standard economic preference frameworks, political liberalism, and social justice.

\footnotetext{
${ }^{16}$ Perfectionists typically ascribe to an essentialist ideal of human nature (Hurka, 1993). Strong perfectionism then is "comprehensive in its ranking of goods and ways of life, coercive in its means of pursuit, pure in its (exclusive) concern for the good life, and state-centred in its principled preference for the state as the direct and primary agent of the promotion of the good life" (Chan, 2000, p 16). Hence, such accounts involve the transition from a particular preferred conception of the good life to a comprehensive political program that serves this conception (Arneson, 2000).

${ }^{17}$ Examples for environmental nudges are the labelling of cars with coloured stickers according to their environmental footprint or the 'Ambient Orb', a little ball that turns red when a customer is using a great deal of energy in his or her household (Thaler and Sunstein, 2008, 200-210). It is questionable to what extent environmental nudges are compatible with individual liberties, as they do not directly command a particular behaviour but can be perceived as coercive (Sugden, 2009).
} 
We have argued that sufficiency goes beyond aspects of 'standard preferences' as used in economics but behavioural economic models are very well able to explain behaviour related to eco-sufficiency. From the perspective of philosophy, this problem is related to 'higherorder volitions' and aspects of personal identity, which are not necessarily revealed in acts of consumption. Eco-sufficiency may generate individual benefits which are not tangible in conventional economic terms and can include non-material benefits. In particular, these may relate to individual perception of the good life.

This is important, in so far as sufficiency is considered to be motivated by individual benefits from a sufficient life which cannot be generalised to all members of society. Imposing obligations derived from an individual perception of the benefits of sufficiency onto others would necessarily cause strong interference in the private sphere and is to be avoided. Public authorities should promote a comprehensive deliberative discourse regarding the benefits and costs of sufficiency without directly interfering in the process.

We show that there is the possibility of sufficiency being in conflict with the demands of distributive justice. Distributive justice implies a lower threshold for consumption in the sense of a social minimum, while eco-sufficiency implies an upper threshold for consumption for ecological reasons. Thoughtful consideration of the demands of social justice in the design of policies motivated by sufficiency is inevitable in order to obtain public support. Sufficiency if a broader phenomenon in society - can also justify the application of alternative approaches to measure welfare and inequality.

Voluntary sufficiency can deliver ecological benefits and can therefore be beneficial for society as a whole. However, we have discussed possible interactions between 'standard' environmental policies and individual sufficiency. The actual choice of policy can be relevant regarding whether ancillary ecological benefits from individual sufficiency beyond the existing standard policy will be effective or not. This, in particular, is the case under regulation by quantities with an exogenous 'cap'. Hence, environmental policies should be designed in a manner that a) secures contributions from non-sufficientarians to achieve ecological benefits, as agreed upon based on a political compromise, and b) that allows for individual contributions to public good provision by sufficientarians beyond the ecological benefits agreed upon.

Overall, the voluntary notion of sufficiency limits the scope of eco-sufficiency for policy making. Voluntary sufficiency largely is a matter of civil society without much need for governmental intervention. Such limitations may be overcome by relaxing the condition of voluntariness. We do not want to claim that non-voluntary environmental policies are problematic in general or that there should be no such policies. But what emerges from our discussion is that non-voluntary sufficiency touches particularly sensitive grounds by interfering with individuals' higher-order volitions, concepts of the good life and identity. Thus, non-voluntary sufficiency is likely to be more effective but incompatible with the values of a liberal society. To overcome this dilemma, further research on sufficiency could focus on how voluntary sufficiency can be promoted more effectively in public discourse. Moreover it should study how sufficiency can be integrated in a more comprehensive 
normative framework related to welfare and social justice, and how its effectiveness for the protection of the environment can be ensured in interaction with other policies.

\section{References:}

Acemoglu, D., Aghion, P., Bursztyn, L., Hemous, D., 2012. The Environment and Directed Technical Change. American Economic Review 102, 131-166.

Adler, M.D., Treich, N., 2015. Prioritarianism and Climate Change. Environmental and Resource Economics 62, 279-308.

Akerlof, G.A., Kranton, R.E., 2000. Economics and Identity. The Quarterly Journal of Economics CXV, 715752.

Alcott, B., 2008. The sufficiency strategy: Would rich-world frugality lower environmental impact? Ecological Economics 64, 770-786.

Alcott, B., 2012. Mill's scissors: Structural change and the natural-resource inputs to labour. Journal of Cleaner Production 21, 83-92.

Anderson, E., 1999. What is the Point of Equality? Ethics 109, 287-337.

Andreoni, J., 1990. Impure Altruism and Donations to Public Goods: A Theory of Warm-Glow Giving. The Economic Journal 100, 464-477.

Arneson, R.J., 2000. Perfectionism and Politics. Ethics 111, 37-63.

Arrow, K.J., 1963. Social choice and individual values. John Wiley \& Sons, New York.

Baumol, W.J., Oates, W.E., 1971. The use of standards and prices for protection of the environment. The Swedish Journal of Economics 73, 42-54.

Bénabou, R., Tirole, J., 2006. Incentives and Prosocial Behavior. American Economic Review 96, 1652-1678.

Bénabou, R., Tirole, J., 2011. Identity, Morals, and Taboos: Beliefs as Assets. Quarterly Journal of Economics $126,805-855$.

Berlin, I., 1969. Four Essays on Liberty. Oxford University Press, Oxford.

Bernheim, B.D., 2009. Beyond Revealed Preference: Choice-Theoretic Foundations for Behavioural Welfare Economics. Quarterly Journal of Economics 124, 51-104.

Bowles, S., 2004. Microeconomics - Behavior, Institutions, and Evolution. Princeton University Press, Princeton and Oxford.

Brennan, G., Pettit, P., 2004. The Economy of Esteem. Oxford University Press, Oxford.

Buchan, N.R., Johnson, E.J., Croson, R.T.A., 2006. Let's get personal: An international examination of the influence of communication, culture and social distance on other regarding preferences. Journal of Economic Behavior \& Organization 60, 373-398.

Buchholz, W., Cornes, R., Rübbelke, D., 2012. Matching as a cure for underprovision of voluntary public good supply, Economics Letters.

Buchholz, W., Peters, W., 2007. Justifying the Lindahl solution as an outcome of fair cooperation. Public Choice $133,157-169$.

Chan, J., 2000. Legitimacy, Unanimity, and Perfectionism. Philosophy and Public Affairs 29, 5-42.

Cooter, R., Rappoport, P., 1984. Were the ordinalists wrong about welfare economics? Journal of Economic Literature XXII, 507-530.

Cornes, R., Sandler, T., 1996. The Theory of Externalities, Public Goods, and Club Goods, 2nd editio. ed. Cambridge University Press, Cambridge.

Demaria, F., Schneider, F., Sekulova, F., Martinez-Alier, J., 2013. What is Degrowth? From an Activist Slogan to a Social Movement. Environmental Values 22, 191-215.

Dixit, A., 2004. Lawlessness and Economics: Alternative Models of Governance. Princeton University Press.

Dixit, A., Olson, M., 2000. Does voluntary participation undermine the Coase Theorem? Journal of Public Economics 76, 309-335. 
Dworkin, R., 2000. Sovereign Virtue. Harvard University Press, Cambridge (Massachusetts).

Fischer, C., Grießhammer, R., 2013. When Less is More - Sufficiency: Terminology, Rationale and Potentials. Institute for Applied Ecology Working Paper 2.

Fischer, C., Heutel, G., 2013. Environmental Macroeconomics: Environmental Policy, Business Cycles, and Directed Technical Change. Annual Review of Resource Economics 5, 197-210.

Fischer, C., Newell, R.G., 2008. Environmental and technology policies for climate mitigation. Journal of Environmental Economics and Management 55, 142-162.

Fischer, C., Preonas, L., 2010. Combining Policies for Renewable Energy: Is the Whole Less Than the Sum of Its Parts? International Review of Environmental and Resource Economics 4, 51-92.

Fleurbaey, M., 2009. Beyond GDP: The Quest for a Measure of Social Welfare. Journal of Economic Literature 47, 1029-1075.

Frankfurt, H., 1971. Freedom of the Will and the Concept of a Person. The Journal of Philosophy 68, 5-20.

Frankfurt, H., 1987. Equality as a Moral Ideal. Ethics 98, 21-43.

Frankfurt, H., 2015. On Inequality. Princeton University Press, Princeton.

Guttman, J.M., 1978. Understanding Collective Action: Matching Behavior. American Economic Review 68, 251-255.

Hansjürgens, B., 2000. The influence of Knut Wicksell on Richard Musgrave and James Buchanan. Public Choice 103, 95-116.

Heindl, P., Schuessler, R., 2015. Dynamic Properties of Energy Affordability Measures. Energy Policy 86, $123-$ 132.

Heindl, P., Wood, P.J., Jotzo, F., 2015. Combining International Cap-and-Trade with National Carbon Taxes, in: Gronewald, M., Hintermann, B. (Eds.), Emissions Trading as a Policy Instrument: Evaluation and Prospects. MIT Press, Cambridge (Massachusetts), pp. 123-147.

Hepburn, C., 2006. Regulation by Prices, Quantities, or Both: A Review of Instrument Choice. Oxford Review of Economic Policy 22, 226-247.

Hoel, M., Karp, L., 2002. Taxes versus quotas for a stock pollutant. Resource and Energy Economics 24, 367384.

Hotelling, H., 1931. The Economics of Exhaustible Resources. Journal of Political Economy 39, 137-175.

Hurka, T., 1993. Perfectionism. Oxford University Press, New York.

Huseby, R., 2010. Sufficiency: Restated and Defended. Journal of Political Philosophy 18, 178-197.

Johansen, L., 1963. Some Notes on the Lindahl Theory of Determination of Public Expenditures. International Economic Review 4, 346-358.

Kahsay, G.A., Samahita, M., 2015. Pay-What-You-Want pricing schemes: A self-image perspective. Journal of Behavioral and Experimental Finance 7, 17-28.

Kallis, G., 2011. In defence of degrowth. Ecological Economics 70, 873-880.

Kanschik, P., 2016. 'Eco-sufficiency and Distributive Sufficientarianism - Friends or Foes? Environmental Values (forthcoming).

Kaya, Y., Yokobori, K., 1997. Environment, Energy, and Economy: Strategies for Sustainability. United Nations University Press, Tokyo.

Lange, A., Löschel, A., Vogt, C., Ziegler, A., 2010. On the self-interested use of equity in international climate negotiations. European Economic Review 54, 359-375.

Lange, A., Vogt, C., 2003. Cooperation in international environmental negotiations due to a preference for equity. Journal of Public Economics 87, 2049-2067.

Lindahl, E., 1958. Just Taxation - A Positove Solution, in: Musgrave, R.A., Peacock, A.T. (Eds.), Classics in the Theory of Public Finance. Macmillian \& Co. Ltd., London.

List, C., 2006. The Discursive Dilemma and Public Reason. Ethics 116, 362-402.

Montgomery, W.D., 1972. Markets in Licenses and Efficient Pollution Control Programs. Journal of Economic Theory 5, 395-418.

Newell, R.G., Pizer, Pizer, W.A., 2003. Regulating stock externalities under uncertainty. Journal of 
Environmental Economics and Management 45, 416-432.

Nordhaus, W., 2015. Climate Clubs: Overcoming Free-riding in Climate Policy. American Economic Review $105,1339-1370$.

Nordhaus, W.D., 2008. A Question of Balance. Yale University Press, New Haven.

Nussbaum, M., 1999. Sex and Social Justice. Oxford University Press, Oxford.

Pauen, M., 2007. Self-Determination: Free Will, Responsibility, and Determinism. Synthesis Philosophica 44, 455-475.

Perino, G., 2015. Climate Campaigns, Cap and Trade, and Carbon Leakage: Why Trying to Reduce Your Carbon Footprint Can Harm the Climate. Journal of the Association of Environmental and Resource Economists 2, 469-495.

Pettit, P., 2001a. Deliberative Democracy and the Discursive Dilemma. Philosophical Issues 11, $268-299$.

Pettit, P., 2001b. A Theory of Freedom - From the Psychology to the Politics of Agency. Blackwell Publishing Ltd, Oxford.

Pettit, P., 2012. On the People's Terms. Cambridge University Press, Cambridge (Massachusetts).

Pigou, A., 1912. Wealth and Welfare. London.

Pizer, W., 2002. Combining price and quantity controls to mitigate global climate change. Journal of Public Economics 85, 409-434.

Posner, E.A., Weisbach, D., 2010. Climate Change Justice. Princeton University Press, Princeton.

Princen, T., 2005. The logic of sufficiency. MIT Press, Cambridge (Massachusetts).

Rawls, J., 1971. A Theory of Justice. Harvard University Press, Cambridge (Massachusetts).

Rawls, J., 1985. Justice as Fairness: Political not Metaphysical. Philosophy and Public Affairs 14, $223-251$.

Rawls, J., 1993. Political Liberalism. Columbia University Press, New York.

Rawls, J., 1999. The Law of Peoples. Harvard University Press.

Ritter, H., Schopf, M., 2013. Unilateral Climate Policy: Harmful or Even Disastrous? Environmental and Resource Economics 58, 155-178.

Sachs, W., 1993. Die vier E's: Merkposten für einen massvollen Wirtschaftsstil. Politische Ökologie 11, 69-72.

Sachs, W., 2009. Fair Wealth: Pathways into Post-Development, in: Rethinking Development in a CarbonConstrained World: Development Cooperation and Climate Change. Finland Ministry of Foreign Affairs, Helsinki, pp. 196-206.

Salleh, A., 2011. Climate Strategy: Making the choice between ecological modernisation or living well. Journal of Australian Political Economy 66, 124-149.

Sandel, M.J., 2012. What Money Can’t Buy: The Moral Limits of Markets. Farrar, Straus, and Giroux, New York.

Schüssler, R., 1996. Licht und Schatten des Diskurses. Analyse \& Kritik 18, 208-224.

Schüssler, R., 2011. Climate justice: a question of historic responsibility? Journal of Global Ethics 7, 261-278.

Sen, A., 1967. Isolation, Assurance and the Social Rate of Discount. The Quarterly Journal of Economics 81, $112-124$.

Sen, A., 1987. Commodities and Capabilities. Oxford University Press, India, New Delhi.

Shields, L., 2012. The Prospects for Sufficientarianism. Utilitas 24, 101-117.

Stern, N., 2008. The Economics of Climate Change. American Economic Review: Papers and Proceedings 98, $1-37$.

Stern, N., 2015. Economic development, climate and values: making policy. Proceedings of the Royal Society B 282.

Sugden, R., 2009. On Nudging: A Review of Nudge: Improving Decisions About Health, Wealth and Happiness by Richard H. Thaler and Cass R. Sunstein. International Journal of the Economics of Business 16, 365373.

Thaler, R.H., Sunstein, C.R., 2008. Nudge: Improving Decisions About Health, Wealth and Happiness. Yale University Press, New Haven. 
Tol, R.S.J., 2009. The Economic Effects of Climate Change. Journal of Economic Perspectives 23, $29-51$.

Tol, R.S.J., 2011. The Social Cost of Carbon. Annual Review of Resource Economics 3, 419-443.

Tol, R.S.J., 2012. On the Uncertainty About the Total Economic Impact of Climate Change. Environmental and Resource Economics 53, 97-116.

van’t Veld, K., Kotchen, M.J., 2011. Green clubs. Journal of Environmental Economics and Management 62 , 309-322.

Wackernagel, M., Rees, W.E., 1997. Perceptual and structural barriers to investing in natural capital: Economics from an ecological footprint perspective. Ecological Economics 20, 3-24.

Weitzman, M.L., 1974. Prices vs. Quantities. The Review of Economic Studies 41, 477-491.

Weitzman, M.L., 2014. Fat Tails and the Social Cost of Carbon. American Economic Review: Papers and Proceedings 104, 544-546.

Wicksell, K., 1958. A new principle of just taxation, in: Musgrave, R.A., Peacock, A.T. (Eds.), Classics in the Theory of Public Finance. Macmillian \& Co. Ltd., London, New York, pp. 72-118. 